\title{
Bitácora de Willie Farrell. Pugilismo, escenarios y negocios a ambos lados del Atlántico. (1920-1960)
}

\author{
Willie Farrell's binnacle. Pugilism, scenarios and businesses on \\ both sides of the Atlantic. (1920-1960).
}

Jonathan Palla

Universidad Nacional de San Martín

Recibido: $17 / 10 / 2018$

Aprobado: 28/11/2018

Resumen. El deporte ha sido uno de los dispositivos más poderosos en la construcción de identidades nacionales. Este trabajo trata de reconsiderar la transnacionalización del boxeo y su impronta en la Argentina a través de la trayectoria de Willie Farrell, un pugilista británico que arribó a Buenos Aires a comienzos de la década de 1920. Su recorrido será el hilo conductor para mostrar ámbitos más amplios y articular diversas escalas espaciales de análisis que permitan conjugar distintos contextos en la difusión del pugilismo.

Palabras claves: boxeo, transnacionalismo, trayectorias vitales.

Abstract. Sport has been one of the most powerful devices in the construction of national identities. This work tries to reconsider the transnationalization of boxing and its imprint in Argentina through the career of Willie Farrell, a British pugilist who arrived in Buenos Aires at the beginning of the 1920s. His journey will be the guiding thread to show more broad and articulate various spatial scales of analysis that allow to combine different contexts in the diffusion of pugilism.

Keywords: boxing, transnationalism, life trajectories.

\section{Propuesta}

Generalmente los estudios sociales sobre el deporte y su difusión nacional, limitan el objeto en tanto que invención de la modernidad europea y lo confinan 
únicamente como una exportación británica a sus áreas de influencia. ${ }^{1}$ Aquí se reconsiderará la transnacionalización del boxeo y su impronta en la Argentina, a través de la trayectoria del boxeador británico Willie Farrell. Ampliando de tal modo la escala, se propone reflexionar las relaciones entre centros y márgenes y el movimiento entre diversos contextos. Para ello recuperamos las perspectivas de historiadoras e historiadores que han dado nuevas direcciones a la Historia Cultural y han problematizado una aparente contradicción entre miradas micro y macro. ${ }^{2}$ En este asunto también fueron y son indispensables los trabajos que han demostrado que las miradas periféricas y cruzamientos de escalas enriquecen nuestra noción de causalidad histórica y permite hallar dinámicas novedosas para los procesos sociales. 3

En una primera parte del artículo se desarrollan los principales momentos, características y oposiciones del pugilismo estilo inglés, durante las décadas iniciales del siglo XX en el escenario rioplatense. A continuación, indagaremos la articulación de diversas escalas espaciales de análisis: diferentes zonas y circuitos que siguieron los boxeadores en movimiento por el planeta. Zonas que si bien no parecían encontrarse en una misma jerarquía de legitimidades, prestigios y réditos, sí parecen entrecruzarse. Para tentar un acercamiento a dicho fenómeno también se indaga, en esa sección, el surgimiento del pugilismo como una actividad en el límite entre lo ilícito y lo legítimo y como una práctica en la intersección entre el deporte y el espectáculo. Luego, se analiza la etapa que se abre hacia 1920 con la difusión masiva del espectáculo boxístico en Buenos Aires, el surgimiento de ídolos populares y las luchas alrededor de su reglamentación institucional. Finalmente, se reconstruyen

\footnotetext{
1 Para un balance de los estudios sociales del deporte en América Latina ver ALABARCES, P. "Deporte y sociedad en América Latina: un campo reciente, una agenda en construcción"; en Anales de Antropología, UNAM. Vol. 49 N.1, 2015.

2 Así, por ejemplo, Davis en su León, el africano reconstruye una microhistoria global que busca conexiones y encuentros entre mundos no fácilmente reconciliables. Ver Davis, N. León El africano. ED. Univ de Valencia, 2008. Por su parte, es a través de un experimento sobre la latitud, los esclavos y la Biblia que Ginzburg sigue la biografía Jean Pierre Purry para hacer visible los intentos de unificar el mundo cuando la conquista europea. Ver Ginzburg, C. La latitud, los esclavos, la Biblia: Un experimento de microhistoria. Disponible en http://www.jcortazar.udg.mx/sites/default/files/GINZBURG.pdf Mientras tanto Revel, con sus discontinuidades y variaciones de escala, ha leído disímiles obras historiográficas intentando demostrar que la oposición entre macro y micro parece insuficiente. Ver Revel, J. Micro versus Macro: escalas de observación y discontinuidad en la historia. En Tiempo Histórico $\mathrm{N}^{0} 2 / 15-16 /$ Santiago de Chile 2011.

3 Ver PUTNAM, Lara. "The Transnational and the Text-Searchable: Digitized Sources and the Shadows They Cast”. American Historical Review. vol. 121, n. 2, 2016, p. 377-402; Scott, Rebecca J. "Small-Scale Dynamics of Large-Scale Processes", en The American Historical Review, Vol. 105, No. 2 (Apr., 2000), pp. 472-479
} 
procesos de conexión y trasferencia entre diferentes contextos sociales a partir de la trayectoria vital del boxeador británico Willie Farrell.

\section{Boxeo: jóvenes, marineros, libros y espectáculos}

Una primera etapa dirimió la disputa entre dos tipos de boxeo, el francés o savate y el inglés. Según algunas memorias, en Buenos Aires, los franceses Mathieu y Dupont poseían un buen número de discípulos a los que enseñaban un boxeo mixto donde se combatía tanto con puños como con las piernas. Ese tipo de lucha se combinaba con otras formas de atletismo como el juego de bastón y se enseñaban en unas pocas instituciones donde se fomentaba la gimnasia y la esgrima. Sin embargo, como en el resto del mundo occidental, sería el boxeo de estilo inglés el que se impondría.

$\mathrm{Al}$ menos hasta el primer cuarto de siglo $\mathrm{XX}$, tenemos una etapa inicial de pioneros que actuaron como profesores y propagandistas. Según Cesar Viale, fueron los que prepararon y alentaron a los aficionados y lucharon contra los prejuicios 4 . Tenían un entusiasmo juvenil y fueron los nativos que se ocupaban de fortalecer la musculatura y que querían practicar boxeo, carrera, lucha o bastón. Los llamaban locos, porque, según los primeros cultores, estas prácticas no habían sido comprendidas aun en la Gran Aldea. Estos muchachos eran orientados por algunos mecenas de la atlética porteña, como el Dr. Delcasse que ofrecía su gimnasio y pista de trotar, ambos instalados en su quinta de la zona del barrio de Belgrano, a individuos de todas edades que se entrenaban en pareja o en equipos en distintas disciplinas. Viale agrega que se trataba de una práctica democrática dado que "sin averiguar el origen se admitía allí a quien quiera que llegase animado por legítimas y sanas pretensiones". 5 De 50 a 100 individuos de todas edades se entrenaban en pareja o en equipos en distintas disciplinas. Era -dice Viale- un centro de alegría masculina y compañerismo. Otro de esos mecenas fue Jorge Newbery, un sportman elegante al que algunos jóvenes porteños tomaron de modelo. "Newbery nos atrajo"6 recuerda Cesar Viale. La instrucción se complementaba además con una serie de publicaciones e imágenes puestas en circulación a nivel planetario. "Teníamos -

\footnotetext{
4 VIALE, Cesar, El deporte argentino, Bs. As., A. García Santos, 1922.

5 Ibid., pp. 49-50

6 Ibid., p. 50
} 
continua Viale- libros y revistas extranjeras que tenían fotografías de Corbett y Fitzsimon, campeones mundiales admirables".7 Aquellas primeras generaciones serán quienes luego hacia 1908 funden el Buenos Aires Boxing Club. Luego, en una segunda etapa promediando la década de 1910, la incorporación de otros jóvenes fue fundamental para el surgimiento de los primeros profesionales hechos en el país: Luis Ángel Firpo, José Lectoure, Jorge Cobos Daract, Luis Galtieri, Julio Perez, Elio Plaissant, Vicente Ostuni, y Julio Beretta, entre otros. El primer boxeo enseñado por Newbery y la legión de profesores ingleses y norteamericanos era más bien una esgrima de puños, un boxeo mecánico donde trataba de evitarse la sangre y el K.O. En cambio, las nuevas generaciones hicieron una preparación más disciplinada, de endurecimiento muscular y contracción abdominal, con más resistencia al castigo y dándole menos importancia a la parada.

Pero entre los puntales que instalaron el pugilato inglés en esta región, uno de singular importancia fue el arribo de viajantes ingleses, irlandeses, escoceses, galeses y estadounidenses, italianos, australianos, etc. que portaban consigo la práctica. ${ }^{8}$ Según Viale, la imposición del boxeo de estilo inglés en Buenos Aires, tuvo que ver con peleas sostenidas por sujetos de sangre sajona, de paso por esta ciudad. 9 Incluso entre los factores que se subrayan en la personalidad de Newbery y sus saberes sobre pugilismo, se destaca el hecho de provenir de las universidades norteamericanas donde se supone que habría adquirido su condición de boxeador. En Buenos Aires, Newbery habría organizado combates para algunos clubes sociales de la elite local y allí los muchachos nativos se enfrentaban "al negro este o aquel y a cuantos marineros extranjeros solían invitarse". ${ }^{10}$

Dan Donelly, Paddy Mc Carthy, Abelardo Robasio, Alfred Culpín, Billie Edward, Willie Gould, Gustavo Lenevé, son los nombres de los mejores boxeadores viajantes que orientaron la enseñanza desde algunos reductos que los contrataban: entidades cómo el Club Gimnasia y Esgrima, el Circulo de Armas, el Club del

7 Ibid., p 51

8 Hasta el momento el registro más antiguo que poseemos sobre un combate en la ciudad porteña corresponde al año 1829. El periódico de la comunidad inglesa en Buenos Aires, el British Packet and Argentine News, publicó noticias sobre un match que enfrentó a un inglés y a un estadounidense, en un local cercano a Retiro. Ver British Packet, 24 de octubre de 1829

9 VIALE, Cesar. Ob cit. Pp. 46.

10 Ibid., p. 51. 
Progreso, El Círculo de Jóvenes Cristianos, etc. Es de destacar que son aquellos migrantes llegados desde otros puntos del Atlántico los que detentarán los primeros títulos disputados en los incipientes torneos nacionales y sudamericanos. Así, por ejemplo, Willie Gould fue un marinero irlandés que detentaba el título de campeón sudamericano de todos los pesos. A su vez Gould obtuvo su título al vencer, en agosto de 1908, al francés Alfred Culpin, primer profesor del Buenos Aires Boxing Club y hasta entonces invicto en el país. ${ }^{11}$ La contienda se desarrolló en el campo de la Sociedad Sportiva Argentina. La revista Caras y Caretas dedicó una página completa de imágenes sobre dicho combate. ${ }^{12}$

El proceso de difusión del boxeo en Buenos Aires se inscribió de tal modo en una variante de escalas y múltiples vertientes. En ese sentido, la zona inmediata al puerto de Buenos Aires fue uno de aquellos ámbitos en los cuales comenzó a practicarse el boxeo en el Río de la Plata. En dicho espacio se continuaron las trayectorias onomásticas de profesores asociados a los clubes de la buena sociedad porteña. Las celebraciones en honor de los oficiales del buque inglés Cambrian o las que se realizaron en honor de los marinos del Pelorus contaron, entre otras competencias atléticas, con la del boxeo. En esos asaltos combatieron generalmente aquellos profesores: los de las tripulaciones y los locales; aunque -como queda dichoentre los profesores locales también se cuenten antiguos tripulantes extranjeros instalados de modo permanente o semi-permanente en Buenos Aires. Asimismo, combatían jóvenes de las familias porteñas acomodadas que aunque no se identificaran como profesores eran la vanguardia de la falange que impulsaba la nueva actividad entre los nativos. Wilkinson, Newbery, Viale, Nazar Anchorena y Delcasse fueron los más reconocidos. Pero también transcurrieron las trayectorias de luchadores nautas anónimos. Por ejemplo, allí se efectuaban torneos entre boxeadores navegantes de diversas embarcaciones, boxeadores a los que las los nativos designan como toscos o sin técnica, que practicaron el boxeo en los ratos de ocio, por algunas libras, mientras sus naves permanecían momentáneamente ancladas en los puertos. ${ }^{13}$ Sin embargo, ellos también ayudaron a cimentar la práctica

\footnotetext{
11 Ver semblanza de Gould en El Gráfico de 21 de febrero de 1941.

${ }^{12}$ Caras y caretas, Buenos Aires, 29/8/1908, $\mathrm{n}^{0}$ 517, p. 62.

13 Ver las memorias de Enrique Wilkinson comentadas en Citado en Anuario del Club de Gimnasia y Esgrima. 110 años en la historia del deporte argentino. Buenos Aires, 1990, p. 54. Otro de aquellos primigenios impulsores del boxeo, José Oriani, también ha dejado su memoria en un texto editado en 1968 por la Federación Argentina de Box, titulado Generalidades del box.
} 
pugilística entre los pioneros y los primeros profesionales nativos. En ese sentido, las memorias de los primitivos impulsores locales destacan la actividad fundacional de The Mission to seamen, de la calle San Juan, y la actividad de promoción de quien dirigía dicha institución, el Reverendo Henry Brady¹4. Las crónicas de publicaciones masivas como Caras y Caretas, las del periódico Crítica, los ya citados registros legados por los primeros difusores nativos del boxeo, insisten en que los boxeadores aficionados fueron reclutados entre los marineros de turno en Buenos Aires. Así, por ejemplo, Erique Wilkinson, uno de los boxeadores nativos pioneros y que llegó a combatir en exhibición con el campeón mundial Jack Johnson en su paso por esta ciudad, rememoraba cómo, durante los primeros años, el puerto servía para que los pugilistas locales se curtieran enfrentando a marineros extranjeros. "Se trataba -dice Wilkinson- de tipos exóticos con los brazos y el pecho tatuados que aceptaban una pelea por una libra. No sabían demasiado de box, peleaban a trompada limpia, pero eran encarnizados." 15

Por otra parte, en sus comienzos el boxeo no se redujo a una práctica higienista y de cuidado físico, sino que desde muy temprano se desarrolló como una actividad en el límite entre el deporte y el espectáculo. En sus memorias, Viale anota que marineros ingleses o estadounidenses realizaban boxeo inglés en teatros de última categoría. Incluso, el afroamericano Percival, que llegó a Buenos Aires en 1880 como profesional contratado por el Club Gimnasia y Esgrima, -sigue Viale- era más un clown grotesco que un boxeador. ${ }^{16} \mathrm{Y}$ efectivamente, aquellos marinos combatían entre sí -con o sin guantes - no solo en el puerto, sino también en bares, salones de baile, teatros, en clubes, terrenos baldíos y otros locales. Teatro y pugilismo, o circo y pugilismo, formaron parte de un mismo programa de variedades. Un ejemplo notorio de esa temprana mixtura entre deporte y espectáculo está contenido en el recuerdo de un combate efectuado el lunes 5 se septiembre de 1892, en cual el británico Tom Bull

\footnotetext{
14 The Mission to seamen era una institución británica de orientación anglicana (la más antigua de las iglesias reformadas en la Argentina), diseñada para atender a los marinos británicos en su arribo a Buenos Aires. Esta sociedad misionera fue fundada en 1856 y ofrecía servicios religiosos a los marinos en los puertos británicos y coloniales. Sus comienzos se remontan a 1907 como parte de la celebración del jubileo por sus 50 años de existencia, cuando llegó a Buenos Aires el Reverendo A. Karney, quien fue recibido en el salón de la iglesia de San Juan, que estaba muy cerca del nuevo puerto de la ciudad y donde dicha institución desplegaba su actividad. Ver SEIGUER, Paula. Jamas he estado en casa. La Iglesia anglicana y los ingleses en la Argentina. Buenos Aires, Editorial Biblos, 2017.

15 Citado en Anuario del Club de Gimnasia y Esgrima. 110 años en la historia del deporte argentino. Buenos Aires, 1990 Pp. 54.

16 VIALE, Cesar. Ob cit., p. 46.
} 
derrotó a su compatriota Alexander Gibb. Dicho encuentro se realizó en el Teatro de la Zarzuela.

\section{La geografía del boxeo y la intersección entre lo legítimo y lo ilegal.}

Pero en ello se adivina otro vector que atraviesa el desarrollo y difusión del boxeo en el área rioplatense: la prohibición, o mejor dicho una zona intermedia entre la legitimidad y la prohibición. ¿Cómo es esto? Dos días después del enfrentamiento entre Bull y Gibb, el Concejo Municipal de la Capital Federal prohibió la práctica del boxeo por iniciativa del concejal Carrasco, quien sentía repugnancia por el pugilato. ${ }^{17}$ Sin embargo, esta prohibición no eliminó al boxeo que, como espectáculo, siguió existiendo en la periferia inmediata de la ciudad (Mercado Central, Lomas de Zamora, Avellaneda); y, por otra parte, en forma de eventuales exhibiciones autorizadas por la Municipalidad continuó en clubes exclusivos de la propia ciudad de Buenos Aires.

El estado legal cambiante de este deporte redefinió la geografía del mundo del boxeo rioplatense. De tal modo existió una circulación de boxeadores en la propia región. En sus memorias, Angel Auzzani comenta que "bien pronto una leal competencia con chilenos y uruguayos obró para cimentar la afición y, diré de paso que, tanto en la nación trasplatina como en la trasandina el pugilato había hecho raíces antes que en la nuestra" ${ }^{18}$ Por lo tanto, la prohibición porteña aumentaba la circulación de aquellos que intentaban hacer del pugilismo su medio de vida. Los primeros profesionales surgidos en el país obtuvieron su diploma en Montevideo. Dirigirse a Montevideo y/o a Santiago de Chile para ingresar al profesionalismo, era la constelación que seguían por entonces los boxeadores argentinos y por eso la que siguió el propio Firpo, máximo ídolo proyectado a escala internacional, antes de probar suerte en los Estados Unidos. Asimismo la puja hacia lo que por entonces se llamaba el box libre en Buenos Aires fue militada en conjunto por boxeadores argentinos y uruguayos: en efecto, el 13 de octubre de 1922, profesionales uruguayos y argentinos presentaron al Honorable Concejo Deliberante una solicitud pidiendo la derogación del Art. 1081 del digesto municipal y pidiendo la organización definitiva

17 La Nación, 08 de Septiembre de 1892.

18 AUZZANI, Ángel, El boxeo. Córdoba, Ediciones Deportivas Ex Conde, 1953, p. 525. 
de una ordenanza reglamentada que permitiera los espectáculos de boxeo en la Capital Federal. ${ }^{19}$

Por lo tanto, aunque ameritaría un tratamiento especial en otro texto, pareciera ser que a nivel global se dibujan algunos entrecruzamientos entre distintos ejes o zonas planetarias de boxeo. Por lo menos entre 1890 y 1914 el eje principal que se había erigido era la zona anglófona de Estados Unidos, Inglaterra y Australia. Según las investigaciones de Matthew Taylor, para ese período, esa zona tuvo el récord competitivo de 301 de los boxeadores profesionales más destacados del planeta. Fueron también empresarios de esta zona los que ofrecieron las sumas más jugosas para promocionar los espectáculos de pugilismo en los que se disputaban los títulos mundiales. ${ }^{20}$ Dentro de ese eje anglófono, Estados Unidos le comenzaría a disputar la primacía a Inglaterra desde al menos la segunda década del siglo XX.

Pero pareciera también que en Sudamérica se iba formando otro eje, sin duda subalterno a aquel, que es el de Santiago de Chile, Buenos Aires y Montevideo. Entre ambos ejes aparentemente hubo cruces, mucho antes de la explosión de Firpo. Aunque por ahora solo se trate de un indicio, al profesor Percival, una nota publicada en Caras y Caretas, le otorgó un prestigio conseguido con anterioridad a su arribo a Buenos Aires, en "ruidosas peleas en Inglaterra, Estados Unidos y Australia" ${ }^{21}$ Además la nota agrega que Percival tiene un hijo argentino de 12 años, "al cual educa especialmente en el arte que él profesa, y tiene la esperanza de llevarlo a Inglaterra" ${ }^{22}$.

Y esos cruces ponían en resonancia algunas cuestiones que sobrepasaban al mero pugilato. Hombres como Percival o King o Dan Donelly fueron afrodescendientes que llegaron a Buenos Aires y se dedicaron al boxeo ofreciendo exhibiciones o instalando academias de pugilismo o trabajando como docentes atléticos en los clubes de la buena sociedad porteña. Comenta una publicación de 1901: "el último asalto habido en el Club del Progreso entre los boxeadores James King, recién llegado de Baltimore, y el profesor del Club, señor Jaquier, ha puesto de

19 El petitorio y la nómina de boxeadores firmantes fue publicada en Crítica el mismo 13 de octubre de 1922.

20 TAYLOR, Matthew, "The global ring? Boxing, mobility and tansnational networks in the anglophone world, 1890-1914"; en Journal of Global History, Vol. 8 02/07/2013, pp. 231-255

21 Caras y caretas (Buenos Aires). 23 de noviembre de 1901, n. ${ }^{0} 164$, pp. 30 22 Íbid. 
moda el pugilato en Buenos Aires".23 Una toma fotográfica de Percival y King en Buenos Aires muestra dos combatientes afroamericanos en una escenografía que tiene de fondo a la bandera de los Estados Unidos. Estos cruces son factibles si pensamos que en Estados Unidos existieron entre 1902 y 1932 campeonatos por el título de pesos pesados en los que participaron solamente afrodescendientes porque muchos blancos se negaban a pelear con negros. ${ }^{24}$ Muchos boxeadores buscaron horizontes en tierras más liberales en cuestiones raciales. Así, por ejemplo, Francia fue de particular atracción para los boxeadores y músicos afroamericanos que percibían a ese país como más progresista porque aceptaba a quienes no eran blancos. Sam Mcvea fue a Paris en 1907, le siguió Jack Johnson y Joe Jennette, los top de los negros. Mcvea viajó por Inglaterra, Francia, Bélgica, Australia, Panamá y también por la Argentina.

\section{Instituciones, mercado y mega eventos.}

$\mathrm{Al}$ comenzar la segunda década del siglo $\mathrm{XX}$ a las páginas de diarios que cada vez más hablaban del boxeo, se sumaron las revistas especializadas o las que, refiriéndose al deporte en general, dedicaron tapas y su mayor cantidad de páginas a las cuestiones del ring. En octubre de 1922 Crítica diseñó la sección Noticiario de Box que, desde abril de 1923, apareció en las primeras páginas y ocupó la tapa del diario cuando pelearon campeones mundiales ${ }^{25}$. También en octubre del 1922 comenzó a publicarse el Sport Ilustrado, donde la mayor parte de las notas se dedicaron al boxeo.

No es casual entonces que el Círculo de Prensa se sumara a un conjunto integrado por clubes sociales, instituciones militares y clubes de boxeo que durante

23 Íbid.

24 Se diferenciaba entre Campeón y Campeón Absoluto. Hasta 1908 Jack Johnson fue Campeón de los pesos pesados negros. Luego de su combate (en Sídney) con el canadiense Burns se convierte en campeón absoluto (1909). Por entonces no fue la derrota por sí sola la que pintó un escenario difícil para Burns, lo fue más aun la censura que pesó sobre él por haber aceptado medirse con un negro. Inmediatamente corre el rumor de que un ex campeón, Jeffries, reaparecerá para impedir que el título de campeón recaiga sobre un hombre de color. De todos modos, Burns contaba con un consuelo dado que no aceptó esa pelea por mera conciencia anti racista. Había exigido en Australia la suma de 150.000 fr gane o pierda, mientras que Johnson solo recibirá 25.000 en cualquiera de ambos casos. Estos elementos no dejan de recordar la asimilación que la escritora Oates hizo al decir que la historia del boxeo en los Estados Unidos es la historia del negro de Norteamérica. Ver OATES, C. Del boxeo. Buenos Aires, Punto de Lectura, 2012.

25 Ver SAÍTTA, Sylvia. Regueros de tinta. El diario Crítica en la década de 1920. Buenos aires, Ediciones Siglo XXI, 2013. 
1920 fundaron la Federación Argentina de Box. Su presidente, Cesar Viale, lo era a su vez del Comité Nacional de Deportes. Cada institución aportaría dos delegados representantes a la FAB y la Comisión Directiva funcionaría en las instalaciones del Club Universitario de Buenos Aires. Asimismo, la FAB nacía bajo la dirección del Jockey Club. Por eso, cuando la federación pidió al gobierno que levantara la prohibición que pesaba sobre el boxeo profesional en la ciudad, una de las razones esgrimidas fue que la FAB estaba constituida por los centros más caracterizados del país.

Ese mismo año además se enviaron representantes de todos los pesos al campeonato internacional de Montevideo. Una incipiente organización institucional que abarcaba esa escala tri-nacional se llevó a cabo durante la IV Olimpiada Latinoamericana, cuando la FAB formó la Confederación Sudamericana de Box junto a la FB de Chile y la FB de Uruguay.

En esa década además se desarrollaron los departamentos de sports en las grandes tiendas, como por ejemplo la de Gath \& Chavez. Si bien desde finales del siglo XIX las tiendas porteñas vendían algunos artículos como por ejemplo guantes de box, hasta entonces estos se anunciaban dentro de un conjunto de mercancías de entretenimientos para niños y jóvenes. Pero desde los años de 1920 las secciones especializadas en artículos deportivos se anunciaban como tales y concentraban una serie de adminículos que para el caso del boxeo incluían guantes de distintas onzas, punchinballs, calzado adecuado para esa disciplina, bolsas de lona para ser rellenadas con arena, pantaloncillos coloridos, aparatos y manubrios gimnásticos, sogas, etc.

Con el fenómeno Firpo asistimos a la conversión definitiva del boxeo en cultura nacional. ${ }^{26}$ En octubre de 1922 se realizó el combate entre Firpo y el australiano Tracey en el Sportivo Barracas, y fue un evento verdaderamente masivo. Luego de la pelea en el Sportivo, Luis Angel Firpo regresó a Estados Unidos y combatió en el Madison, máximo centro del espectáculo deportivo mundial. Con la masiva popularización del pugilato brotaron los promotores y managers, puesto que el boxeo se presentaba como un nicho de inversión para obtener ganancias y en

$26 \mathrm{El}$ seguimiento que hacen los medios gráficos de la campaña de Firpo convoca a aficionados y a los que no siguen habitualmente el pugilismo. La noticia de que Firpo había vencido en los Estados Unidos al marinero Maxted repercutió jubilosamente entre los aficionados al deporte y aun la apatía de los pocos indiferentes fue dominada por los entusiasmos de las manifestaciones callejeras. 
consecuencia muchos se lanzaron sin tener el menor conocimiento sobre los engranajes del pugilismo. ${ }^{27}$

En un contexto signado por una legión cada vez más nutrida de jóvenes partidarios del boxeo, el surgimiento de un ídolo masivo como Firpo y hombres de negocios dispuestos a extraer beneficios de una actividad que con tanta adhesión popular, en principio, prometía rentabilidad, el año de 1922 se produjo un cisma en la FAB encabezado por aquellos clubes que acusaban a la dirección de la institución de no hacer lo suficiente por lograr la legalización del boxeo rentado en la Capital Federal y en consecuencia fundaron la Asociación Argentina de Boxeo (AAB). Crítica que, en todo este asunto, actuó como un verdadero órgano propagandístico de los secesionistas, informó que la nueva entidad "se pondrá bajo la dirección inmediata de la Municipalidad a los efectos del control y de este modo se habrá dado un gigantesco paso hacia la implantación definitiva del boxeo"28

La prohibición del boxeo como espectáculo público estuvo vigente en la Capital Federal hasta el 3 de enero de 1924. La enorme presión popular que surgió tras el choque entre Jack Dempsey y Luis Ángel Firpo, el 14 de septiembre de 1923 en el Polo Grounds de New York, presionó a que se levantara la proscripción reglamentada en el Art. 1081 del digesto municipal. El gobierno de la Ciudad puso como condición la fusión de las entidades del boxeo en una sola, la FAB. Acto seguido se creó la Comisión Municipal de Boxeo de la Capital Federal que, en un lapso de 30 días, debía normalizar la actividad y se le otorgó a Firpo la licencia $\mathrm{N}^{0} 1$. Recién allí comenzaría la era del pugilismo controlado en Buenos Aires.

\section{Un experimento de microhistoria a ambos lados del Atlántico. La trayectoria de Willie Farrell.}

\footnotetext{
27 A poco de ser sancionada la ordenanza de box por el Honorable Concejo Deliberante, el 23 de diciembre de 1923 y promulgada por el Estado municipal el 3 de enero de 1924, Malek y Laktman organizaron peleas en el estadio de River Plate, pero perdieron 250.00o pesos. Se suceden listas de hombres y sitios en los que se organizaron combates: Emilio Mazzuchelli, en el viejo Luna Park; José Agüero en L'aiglon y el Hippodrome; Agusti en el teatro Coliseo; otro hombre de apellido Costo en el Parque Romano; Furlano en el mismo lugar. Estos datos se obtienen de las crónicas de publicaciones como El Gráfico y de los anuarios de boxeo o Guías Pugilisticas que ponían a disposición del lector cifras y datos históricos.
}

28 Crítica 25 de octubre de 1922. 
Lo dicho hasta aquí permite insinuar que para comprender la dinámica histórica del desarrollo y difusión del pugilismo en Buenos Aires debemos tener en cuenta los circuitos y los flujos globales de los pugilistas. Pero ćcómo eran esos circuitos? ¿Era por azar o como una aventura personal que un boxeador llegaba desde tierras tan lejanas a Buenos Aires? ¿Qué conocía de este país o esta ciudad antes de arribar? ¿Llegaba solo o acompañado? ¿Lo recibía alguien? Para comenzar a tentar una respuesta seguiremos la trayectoria de uno de estos boxeadores en movimiento, de modo tal que nos lleve como un hilo conductor para mostrar ámbitos más amplios.

Willie Farell nació en Birmingham, Gran Bretaña, el 9 de abril de 1893. Fue hijo de William Farrell y Winnie Bishop, artistas del music hall y debutó como boxeador en 1912 en The Ring, un estadio de boxeo que comenzó a funcionar desde 1910 en Blackfriars Road, en Southwark. Fue apadrinado entonces por los propietarios de The Ring, Dick Burge y su esposa Bella, quienes lo bautizaron como the actor- boxer. Contratado por esa empresa, Farrell, posiblemente influenciado por sus padres comediantes, combinaba su arte sobre el ring con el canto después de la lucha. ${ }^{29}$ Efectivamente, las gráficas y los anuncios de sus combates en la prensa británica lo presentan como Willie Farrell, el actor-boxeador.

El 22 de junio de 1916, con 24 años, se casó con Grace Eleonor Thorpe de 19. La boda se realizó en Londres en el mismo distrito de Southwark. Parece que allí la profesión de artista y pugilista rentado era un oficio social y legalmente aceptado, pues el certificado nupcial menciona la profesión de Willie como "boxeador profesional". Y también aparece mencionado el padre de Willie, William, quien figura como artista del music hall.

En su carrera pugilística Farrell se inició dentro del Reino Unido, presentándose en diferentes estadios, clubes y casas de espectáculos de una serie de ciudades como Birmingham, Londres, Liverpool (Inglaterra); Swansea, Cardiff (Gales); Glasgow(Escocia). Durante el mes de mayo de 1920 disputó dos combates en Sidney (Australia). El 11 de julio de 1922 un periódico inglés comentó en su página deportiva que "WF aceptó ser entrenador del Club Universitario de Buenos Aires". 30 El $1^{\circ}$ de agosto del mismo año The Scotman, comentando la pelea de Farrell con Jim

29 Bell, Leslie. Bella of Blackfriars. Odham Press Limited. Londres, 1961. Pp. 179 30 Sheffield Independent 11 de julio de 1922 
Slater en The Ring el día anterior, anunció que dicha contienda "fue la última de aquel ya que se va de Inglaterra para Buenos Aires como entrenador del Club Universitario". No había azar en esta partida, pues como quedó registrado en la prensa británica, el actor boxeador se iba con una propuesta de trabajo en una institución exclusiva como lo era el Club Universitario de Buenos Aires.

Claro que ello no dejaba de contener algún riesgo: en Buenos Aires el boxeo aún no se había profesionalizado y para buena parte de la sociedad porteña y su dirigencia política, el pugilismo era una actividad de bárbaros. Quizá por eso, en septiembre de ese año, Willie desembarcó en Buenos Aires sin su familia. Además su esposa ya llevaba 8 meses de embarazo y a las incomodidades del viaje, posiblemente, se sumara la ausencia de su marido, quien estaría ocupado aquí y no podría dispensarle el afecto y el cuidado necesario, sin otros amigos o familiares que pudieran acudir. Esta probabilidad es más patente si tomamos en cuenta que, cuando el 18 de octubre de 1922, es decir menos de un mes después del arribo, nació en Gran Bretaña su primera hija, Peggy Marie, y según indica su certificado de nacimiento, la niña vivía con su madre en casa de la abuela materna en Londres, 84 de Astbury Road. ${ }^{31}$

Pero ¿por qué Farrell hizo un viaje tan largo y aparentemente con tantos sacrificios? ¿Cual es la red de personas y sucesos en la que se inscribió un viaje que conectaba contextos tan disímiles para un boxeador? En principio debemos considerar que la estrecha relación comercial de la Argentina con Gran Bretaña había hecho surgir aquí tempranamente una colectividad británica importante, si no en número, sí en los aspectos económico y político. Las colectividades anglófonas, entre otras actividades, publicaban en Buenos Aires sus periódicos que, en las diversas secciones, comentaban la actividad cultural dirigida a esa comunidad. Así para los comentaristas del The Buenos Aires Standard:

\footnotetext{
"No es frecuente que un verdadero boxeador británico de jerarquía se vea en Argentina y un hombre como Farrell nunca hubiera hecho un viaje tan largo, sino por el hecho de que los muchachos del University Club lo contrataron para un número limitado de peleas en los rines locales. La gente se estaba cansando de los trapos y el Ejecutivo del Club
}

31 Los certificados de matrimonio y nacimientos de Willie Farrell y su familia han sido facilitados por su familia residente en Londres, quienes lo obtuvieron a su vez de las oficinas y registros oficiales de aquella ciudad. 
Universitario, sabiamente, decidió mejorar las cosas construyendo una estrella en la arena de las espadas" 32

Es decir, el arribo de Willie Farrell tenía que ver con las expectativas del Club Universitario en brindar un espectáculo y una figura de calidad que atrajera público en un medio como el porteño carente de pugilistas verdaderamente notables. Más adelante, en una especie de balance de esta primera estancia de Farrell en Buenos Aires, el mismo periódico comentó que:

\footnotetext{
"durante muchos años, los boxeadores británicos y coloniales han venido a este país para probar suerte contra los exponentes locales del boxeo. Los arribos de hombres de combate han sido de todas las categorías, pero ninguno ha llegado aquí con un mejor carácter que Willie Farrell, ya sea como un luchador deportivo, un hígado limpio o un hombre de carácter moral aprobado”33.
}

La difusión masiva de la actividad pugilística en tanto que espectáculo se ligaba al desarrollo de medios de comunicación masiva y por eso la presentación en sociedad de Willie Farrell se hizo en el semanario El Gráfico que era una de las publicaciones deportivas más importantes entonces. El 23 de septiembre de 1922 esa publicación mencionó al "nuevo huésped", quien fue fotografiado junto a Paddy McCarthy. Este fue el personaje asociado al punto fundacional del boxeo porteño: en 1900 llegó en un buque mercante inglés y gracias a sus lazos con la elite local, se empleó como maestro de boxeo de la Escuela Pellegrini (fundada en 1890) y luego en 1904 en el Club de Gimnasia y Esgrima. En el epígrafe de la foto mencionada, McCarthy aparece como "el famoso speaker", y es que el popular McCarthy también actuaba como presentador en los combates pugilísticos en el Club Universitario. Por su parte, la prensa británica editada en Buenos Aires no dudaba en afirmar que Mc Carthy era el manager de Farrell e informaba al público aficionado que los tickets para los combates de Farrell podrían obtenerse de P. McCarthy en la propia sede del Club Universitario. Asimismo el diario Crítica, más adelante, denunciará que "Willie Farrell aún no ha podido corroborar la fama que traía de la famosa Albión (nombre más antiguo de Gran Bretaña), ni su formidable record tan anunciado por 
McCarthy" ${ }_{34}$ Es decir, las conexiones entre McCarthy y esta primera estancia de Farrell en Buenos Aires parecen bastante fuertes.

Aunque los documentos disponibles hasta ahora han consignado a Farrell como procedente de Birmingham, las referencias periodísticas en Buenos Aires lo adscribían como boxeador irlandés. Por el momento la única filiación irlandesa de Willie encontrada tiene que ver con sus padres, quienes se habían mudado desde Irlanda y se establecieron en Shorditch, al este de Londres. Lo cierto es que para insuflar su reputación, en Buenos Aires, se lo anunció en los medios como poseedor de una racha que incluía sus últimas 20 peleas ganadas por K.O. No obstante, la consulta a los periódicos británicos, a través de los repositorios digitales, para verificar semejante currículo, arrojan otra situación. 35 Aunque ha ganado la mayoría de las peleas, no ha ganado todas y aun entre las que ha ganado, no todas fueron por K.O.

En su debut, el 21 de septiembre, Farrell se enfrentó al uruguayo Bernabé Rivero y tuvo como segundos, en la esquina del ring, a Harold Evelyn y Paddy Mccarthy. Evelyn había llegado al país de la mano de Marcelo Peacan del Saar, primer presidente del Buenos Aires Boxing Club fundado en 1908, tras un viaje que este había realizado por Europa. Desde entonces Evelyn actuó como profesor en su propia academia en Buenos Aires.

Tras el primer combate, Crítica dijo "¿Willie Farrell es un paquete o un tonguero?" El periódico calificó a la pelea como "exhibición de puchinball”, en la que Farrell "juega con un rival que no ofrece lucha y los rounds se suceden monótonos y pesados entre un hombre que no quiere pegar fuerte y otro que pugna por defenderse." Así iban las cosas y en el tercer round "la cara de Rivero es una masa sanguinolenta, un pedazo de carne desuniforme y machucada" 36 Del uruguayo Rivero no se disponen mayores records, salvo unas pocas peleas y ninguna ganada. Aquella noche parece que su estado físico tampoco era óptimo, pues se habla de su "abultado abdomen" Por eso, la nota va a responder a la pregunta inicial que Farrell más que un paquete es un tonguero. Según el diccionario de lunfardo, entre las varias acepciones

34 Crítica 12 de octubre de1922

35 Es posible acceder al repositorio digital de periódicos británicos a través de www.britishnewspaperarchive.co.uk

36 Crítica, 22 de septiembre de1922 
que tiene la palabra "paquete" una es: boxeador fuera de forma, excedido de peso. 37 Tongo, por su parte, aludiría a una componenda ilícita y especialmente en el deporte, aclara el mismo diccionario. El periodista de Crítica insinuó una sospecha más general que incluía no solo al boxeador, sino que también alcanzaba a McCarthy, quien desde la esquina del cuadrilátero le indicaba a Farrell que pegara despacio; el jurado de la pelea también cayó bajo sospecha dado que no intervino para suspenderla y aun el propio Club Universitario porque "casi casi estamos por creer que lo ocurrido anoche, pasa en otro club y ya estaba suspendido o descalificado hasta el portero". 38

El segundo combate de Farrell organizado por el Club Universitario lo cruzó con el uruguayo Abel Adán. El combate duró solamente dos rounds y fue una sucesión interminable de knock downs en los que el uruguayo solo se volvía a levantar para que Farrell volviera a derribarlo. Así las cosas, el segundo de Adán, el profesional Sobral, tiró la esponja en señal de abandono, tal como lo indicaban las reglas cuando un boxeador fuertemente golpeado daba señales de no poder continuar. El referí dio por concluida la pelea y el triunfo para el irlandés39.

El tercer combate de Farrell, también en el Club Universitario, fue nuevamente frente a un boxeador uruguayo, el Indio Loza, y el encuentro volvió a estar teñido de similares sospechas y disputas en la prensa. ${ }^{40}$ ¿Cuándo tendremos -decía Críticauna pelea sin decisiones antojadizas?41 Por su parte, el diario La Unión también coincidió en que la pelea terminó de "forma rara" y se preguntó sugestivamente "¿Por qué razón el referí estaba tan preocupado en que el Loza descubriera la cara?”. ${ }^{42}$ Los sucesos fueron comparados con un match anterior de Farrell, que la gran prensa no había registrado.

37 Hemos utilizado el diccionario de lunfardo disponible en www.todotango.com/comunidad/lunfardo/ 38 Íbid.

39 La razón o8 de octubre de 1922.

40 En el transcurso de la pelea, Loza fue amonestado por el referí por no cerrar los guantes. En el $9^{\circ}$ round, de una pelea que era a 10, Loza protestó por otra amonestación del referí y este terminó la pelea anticipadamente dándole el combate a Farrell. Crítica consignó las protestas del público y, retóricamente se preguntó por qué no fue amonestado Farrell al cometer la misma infracción que Loza.

41 Crítica, 12 octubre de1922.

42 La Unión, 13 de octubre de 1922. 
"La pelea con Loza en sí fue una reedición de la lucha que Farrell sostuvo con Raizero hace tres semanas. Solo que esta vez el adversario del irlandés no huía como aquel alrededor del ring, sino que atacaba con un valor digno de toda admiración. Y Farrell cuyo juego un tanto simple, asombra por la precisión y seguridad con que lo realiza, demostró carecer de recursos suficientes para abrirle la guardia a su valiente adversario."43

En cambio otras hojas consignaron la pelea de modo diferente. Para $L a$ Nación, por ejemplo, esa decisión del referí Méndez fue "acertadísima". Y en su justificación, privilegiaba otro aspecto, a saber: el del espectáculo. "En esa forma dice La Nación- se evitará que en matches que podrían ser excelentes no haya en todo el desarrollo un solo momento de emoción, y tenga por característica una monotonía desesperante".44 Para el Buenos Aires Herald, periódico inglés editado en Buenos Aires, la decisión de Méndez, "que no es común en estos rines, fue recibida con vítores entusiastas de la multitud entre la cual Willie Farrell es muy popular". 45

Con opiniones tan encontradas, el irlandés había dejado una enorme incógnita en el ambiente pugilístico de Buenos Aires. Por una parte, se lo admitía como portador de una fama hecha a base de centenares de peleas e innumerables KO y el precedente de haber ganado por tres veces consecutivas el Ring Belt de Londres; es decir, un campeón proveniente de la mismísima tierra del boxeo, Gran Bretaña. Sin embargo, al mismo tiempo, la mayoría de los reporteros coincidían en sentencias tales como que "Algunos dicen que sus adversarios han sido tres paquetes: Rivero, Adan y Loza", ${ }^{46}$ o que "el irlandés solo ha sido puesto frente a pugilistas de segunda categoría" o que "sus oponentes hasta ahora no han sido más que mediocridades pugilísticas". 47

Un próximo encuentro con el boxeador chileno Abelardo Hevía, calificado como excelente fighter, aparecía, según los medios, como una oportunidad de redención. Dos días antes del combate una gráfica publicitaria del encuentro mostró una caricatura de Hevía sentado sobre el cuerpo vencido de Bray Liam, su último rival. En el mismo dibujo, Farrell aparecía sentado sobre paquetes que llevaban inscriptos los nombres de Rivero y Loza. Y ya vimos lo que significaba paquete en el lenguaje popular de la época y comentamos los estados físicos y trayectorias de los

43 Íbid.

44 La Nación el 13 de octubre de 1922

45 Buenos Aires Herald el 12 de octubre de 1922 (traducción del autor).

46 La Unión el 23 de octubre de 1922

47 La Palabra el 18 de octubre de 1922 y Crítica 12 de octubre de 1922. 
oponentes de Farrell. Aquella pelea con Hevia también tuvo como marco el Club Universitario.

Pero la redención sería breve. Se iba cerrando la primera estancia de Willie en calidad de contratado por el Club Universitario. Unos días antes The Buenos Aires Standard apostaba a que "es de esperar que los muchachos del Club universitario lo persuadan a quedarse un poco más". ${ }^{48}$ Mientras tanto, una quinta pelea de Farrell se anunció: esta vez en el estadio de rugby del Club San Isidro y frente al boxeador argentino Vicente Ostuni. Entonces todo terminó en un escándalo peor a los anteriores: en el 5to round Farrell abandonó la pelea sin que nadie supiera por qué. El diario Crítica habló de Farrell una vez más como "derribador de paquetes" y propuso que se le retirara la bolsa "aunque se enoje Mccarthy".49 The Buenos Aires Standard tuvo una comunicación directa con Willie luego del combate para que explicara lo sucedido y según informó en su edición del 27 de noviembre, el británico recibió un corte en su ojo izquierdo que le obstruyó la visión y le impidió continuar el espectáculo. El periódico no parece haber quedado conforme con la explicación de Farrell, pero a diferencia de los diarios porteños también reclamaba la responsabilidad de Ostuni y su gente en todo este asunto. En su siguiente edición, lanzó: "Si el boxeo no puede llevarse a cabo limpiamente, entonces es mejor suprimirlo". ${ }^{0}$

Presionada, la FAB aplicó una suspensión a Farrell por 3 meses, hasta el $1^{\circ}$ de marzo de 1923. Pero Farell ya había informado que se embarcaría para Londres el $1^{\circ}$ de diciembre y que pensaba volver en abril. Por lo tanto la sanción que decía imponerle la FAB era una fantasía, puesto que, según comenta la prensa, nadie imaginaba que las decisiones de la Federación Argentina fueran tenidas en cuenta en el medio deportivo londinense. Willie Farrell se fue el $1^{\mathrm{o}}$ de diciembre de 1922. Decían que iba a tomar parte en el campeonato inglés de peso welter o welterweight (WW). "Nosotros no le creemos", acotó Crítica.

Tras el escándalo con Ostuni, Harold Evelyng, a quien hemos mencionado más arriba, publicó una carta en Crítica para despegarse de Farrell y de cualquier sospecha de fraude en el deporte. Allí leemos "Actué como segundo de Farrell a pedido de él y de Mccarthy. Tengo en mi poder cartas de ellos que solicitan mi

48 The Buenos Aires Standard, 26 de octubre de 1922.

49 Crítica, 27 de noviembre de 1922

50 The Buenos Aires Standard, 28 de noviembre de 1922 
presencia por conceptuar Farrell de utilidad mis indicaciones y masajes". ${ }^{51}$ Pero las conexiones eran más robustas de lo que Evelyn dejaba ver en esa carta. Evelyn, que además oficiaba de traductor e interprete de Farrell en el ring, proporcionaba alumnos de su academia para que participaran en espectáculos de boxeo como preliminaristas a pedido de Mccarthy. Por otra parte, según The Buenos Aires Standard, Evelyn, declaró que habiendo escuchado antes de la pelea que se había llegado a un acuerdo por el cual Ostuni iba a ganar, se negó a actuar y después de un breve incidente con el árbitro, el señor Rodríguez Jurado, se retiró del ring. Sin embargo, el comité de la FAB decidió aplicarle también una suspensión a Harold Evelyn.

Farrell también actuó, al menos durante su primera estancia, como árbitro de boxeo. Y esto puede ofrecer más datos sobre el funcionamiento de una red de conexiones. El 17 de noviembre de 1922 Crítica comentaba que Willie dirigió combates, disputados entre tripulantes de buques surtos en el puerto, organizados por el Capitán Reverendo Brady en The misión to seamen, en un amplio local en la calle San Juan de la Capital Federal, espacio ligado también al mundo portuario y a la comunidad anglófona. Con la inesperada llegada de Willie Farrell y su manager, el Sr. P. MacCarthy, los muchachos expresaron su agradecimiento enfáticamente y el capellán, el canónigo Brady, le solicitó a Willie que emprendiera el trabajo de referí. Al finalizar el concurso, el canónigo Brady hizo un llamado a Willie Farrell para que ofreciera un discurso. $5^{2}$

Algunas crónicas, como la ya citada Generalidades del Box, de José Oriani, mencionan que los boxeadores aficionados fueron invitados a los festivales de boxeo por el Reverendo Brady. Por su parte, también encontramos al Reverendo enredado con los hombres del Club Universitario y varias veces se desempeñó como árbitro en peleas organizadas por esa institución. Unos años más tarde las memorias de Peacan del Saar publicadas en El Gráfico nos dan pistas para reconstruir las uniones: "Paddy Mc Cartthy... se desempeñaba como verdadero oficial de enlace y reunía a sus invitados. Algunos llegaban orientados por el honorable Canon Brady, director de la Misión de Marineros Británicos y otros por referencias de connacionales”.53

51 Crítica 1 de diciembre de 1922

52 The Buenos Aires Standard, 7 de octubre de 1922.

53 El Gráfico de Buenos Aires, marzo 28, Junio 6 y junio 27 de 1952. (Negritas en el original). 
Individuos como McCarthy y el Reverendo Brady, aparecían como nexos u oficiales de enlace entre hombres de ambos lados del Atlántico, conectando boxeadores europeos con los clubes porteños y otros reductos que impulsaban la práctica pugilística. En dicho circuito resaltaba el área del puerto. Esto incluía además a los espectadores de los combates: un diario editado y dirigido a la comunidad anglófona de Buenos Aires anunciaba que "Se nos ha pedido que declaremos que el Comité del Club Universitario ha fijado precios especialmente bajos para los hombres de los barcos ingleses y norteamericanos en el puerto". ${ }^{54} \mathrm{En}$ estas conexiones, los vínculos entre hombres y clubes nativos de la ciudad y la comunidad británica también tienen un peso fundamental. Otras afirmaciones del mismo periódico van en similar sentido de identificar a la comunidad británica de Buenos Aires en el mundillo del pugilismo: así por ejemplo, frente al combate con Adán, "escuchamos de una fuente confiable que un gran número de aficionados norteamericanos y británicos, ya han reservado sus asientos",55 o también: "Para William debió haber sido bastante reconfortante ver la tremenda asistencia de los fanáticos británicos y estadounidenses en el Club". ${ }^{6}$ Los vínculos entre el Club Universitario y la prensa editada por la comunidad británica en Buenos Aires también parecen estrechos a juzgar por algunas declaraciones en el diario. Quedó registrado anteriormente que aunque The Buenos Aires Standard juzgó negativamente los sucesos del combate frente a Ostuni, también tuvo una comunicación directa con Farrell, una vez concluido el espectáculo. Por otra parte, las afirmaciones de dicho periódico en cuanto a los combates organizados por aquel club nunca tuvieron el tono denunciativo de otras hojas como Crítica. Por el contrario, hallamos sentencias del tipo de: "la clase correcta de gente está patrocinando estas exposiciones realmente admirables del arte de los puños. Buena suerte a los chicos de la Universidad". 57

Seguir el hilo de la trayectoria de Farrell por Buenos Aires también permite arrojar algo de luz sobre las condiciones sociales del pugilismo rioplatense en aquel momento. Para empezar, los encuentros se daban dentro del marco de espectáculos nocturnos. El combate frente a Rivero, por ejemplo, formó parte de un programa que tuvo la inclusión de la orquesta americana Peabody que amenizó los intervalos

54 The Buenos Aires Standard, 11 de octubre de 1922.

55 The Buenos Aires Standard, 6 de octubre de 1922

56 The Buenos Aires Standard, 8 de octubre 1922

57 Ibid. 
poniendo una nota alegre con sus rigetimes, foxtrots, shymis, etc. $5^{8}$ Para el caso Crítica dijo que de no ser por estos detalles las veladas boxísticas son aburridísimas cuando empiezan a media noche. Incluso los combates entre los tripulantes de las embarcaciones en The Mission to seamen se dieron en el marco de variedad de espectáculos, con el propio Brady cantando foxtrots u ofreciendo boxeo entre hombres y perros, etc. Igualmente encontramos en Buenos Aires un espacio pugilístico en el que intervienen con cierta fluidez boxeadores uruguayos y chilenos. Ya mencionamos al comienzo incluso la expresión institucional que esas conexiones se habían dado con la fundación de la Federación Sudamericana de Box. En 1920 se había realizado ya el primer campeonato sudamericano en Montevideo y en 1923 se realizaría en Buenos Aires. De los uruguayos que enfrentaron a Farrell sabemos que al menos Adán había firmado el petitorio de pugilistas para derogar el art. 1081. La participación de Farrell en este medio abona nuestra idea de cruce de ejes o zonas de boxeo anglófonas e iberoamericanas. Las reseñas de los combates además aportan elementos para seguir complejizando dichos cruces con boxeadores viajantes que llegaban de otras zonas del planeta. Por ejemplo, durante la previa de la pelea con Ostuni,

"un negro panameño llamado Reilly, que acaba de llegar aquí con algo de reputación en el juego de boxeo, desafió a todos los participantes en su clase, y fue tan pronto asumido por el conocido Bornetto argentino; por lo que probablemente habrá un poco de sangre negra derramada muy pronto".59

Ahora bien, aunque estos hombres se movieron en una red transnacional importante, la primera trayectoria de Farrell parece mostrar que el boxeo se mantenía aun en gran medida resistente a la regulación y estandarización internacional más amplia. Como quedó anotado, en aquel contexto nadie imaginaba que las decisiones y suspensiones de la Federación Argentina fueran tenidas en cuenta en el medio deportivo londinense al que regresaba Willie Farrell al finalizar 1922.

Por otra parte, algo en lo que insisten los registros es en la pobre calidad de las exhibiciones de boxeo preliminares a la pelea de fondo. Según Crítica ninguno de los oponentes de esas peleas hace gala de boxeador y pareciera que luchan "o por

58 Crítica, 22 de septiembre de 1922

59 The Buenos Aires Standard, 27 de octubre de 1922. 
compromiso o por ver gratis las peleas de fondo". 60 Sobre las preliminares del combate de Farrell contra Hevia, el diario La república comentó que Rabunal y Dandrade intentaron una exhibición, pero fueron suspendidos porque no llegaban ni remotamente a los propósitos perseguidos. Después Cesar La Banca y Américo Álvarez subieron al ring para disputar un match de 5 rounds, pero tampoco resultó este encuentro y fue suspendido al 3er round. ${ }^{61}$ Otro flanco que, según la prensa británica de Buenos Aires, viciaba al pugilismo local tenía que ver con las pretensiones a bolsos exagerados por parte incluso de los boxeadores más mediocres. Para el reportero esa pretensión solo está justificada cuando se trata de mega estrellas del pugilismo: las de Dempsey, Wills o Beckett se pueden entender; e incluso un Firpo tiene derecho a exigir una suma sustancial. Pero es interesante que aquí se vuelva a equiparar la labor de los boxeadores con la de los actores: "Un pugilista tiene naturalmente derecho a una compensación, al igual que un actor; pero ningún actor mediocre soñaría con pedir las grandes sumas que un boxeador similar no dudaría en reclamar antes de exhibir su arte ante el público". ${ }^{62}$ Como sea, este vector al parecer también atravesaba los conflictos institucionales, pues "Los clubes aquí están sintiendo la tensión y es bastante seguro que se tomarán medidas de algún tipo en este sentido dentro de poco. 63

Al mismo tiempo, parece que la deficiencia en la calidad y cantidad de pugilistas no se observaba solo a nivel de los aficionados preliminaristas. ${ }^{64}$ Tal vez por ello a pesar de que se denuncia que Farrell solo pelea con luchadores de segunda categoría, sus méritos son muy poco cuestionados por los medios. El diario La Razón lo expresaba así: "Aunque Farrell se ha enfrentado aquí a boxeadores de segunda categoría, ha demostrado que tiene positivos méritos y que seguramente sea uno de los mejores boxeadores que nos haya visitado." 65 Ante otro encuentro de Farrell, Ultima Hora acota "será una buena oportunidad de presenciar buen box, cosa que se estaba ya haciendo rara entre nosotros”. ${ }^{66}$ Recordemos que según The Buenos Aires

\section{0 Ídem.}

61 La República, 26 de octubre de 1922

62 The Buenos Aires Standard, 29 de noviembre de 1922

63 Íbid.

64 La falta de pugilistas de verdadera calidad es una característica de este medio rioplatense que las publicaciones especializadas de la época, como el Sport Ilustrado, protestan regularmente.

65 La Razón, 25 de octubre de 1922

66 Última Hora, 26 de octubre de 1922 
Standard, el Club Universitario había importado a Farrell justamente para ofrecer espectáculos de mayor calidad. Luego de la pelea con Adán, el mismo diario comentaba que "Farrell está solo en una clase, indiscutiblemente el pugilista más listo que se haya visto en Argentina". ${ }^{67}$

Recordemos: Willie Farrell llegó en un momento complejo para la historia del boxeo porteño. Como quedó dicho más arriba, hacia 1920 un conjunto integrado por diferentes instituciones sociales, deportivas y profesionales formaron la Federación Argentina de Box (FAB). Pero en el año de 1922 y precisamente durante los meses en los que arribó Willie, se produjo un cisma encabezado por las organizaciones que acusaban a la FAB de no hacer lo suficiente por la legalización del boxeo rentado en la Capital Federal. En consecuencia fundaron la Asociación Argentina de Boxeo (AAB). Ningún reducto en el que se practicara boxeo pudo ser neutral ante este conflicto. Y mucho menos podía serlo en Club Universitario, si recordamos que en sus instalaciones funcionaba la Comisión Directiva de la FAB. ¿Cómo se ubicó en dicho conflicto la institución a la que se integró Willie Farrell, en calidad de contratado, es decir el Club Universitario de Buenos Aires? En su edición de 26 de octubre de 1922, Crítica comentaba que: “...de los clubes que realizan peleas actualmente y de los que aun no han manifestado su adhesión a la AAB, son el Boxing Club Buenos Aires y el Club Universitario. Los demás no se deben tomar en cuenta por cuanto no practican el noble deporte". Farrell entonces estuvo inscripto en una red de alianzas y solidaridades que estaba pasando por un momento de redefiniciones y reacomodos. Las insinuaciones sobre combates arreglados, las quejas por un medio lánguido poblado por árbitros deficientes y la falta de boxeadores de mayor calidad, etc. no recayeron exclusivamente sobre los encuentros que tuvo Farrell, sino que eran una constante denuncia en las publicaciones de boxeo y expresaban las luchas entre quienes disputaban el poder y las orientaciones de la práctica y el espectáculo del boxeo. Los combates de Farrell se dieron sobre estas luchas de instituciones y poderes y por ende formaron parte de ellas. Cuando la prensa descalificaba el fallo de un referí, descalificaba al juez designado por la FAB. En el caso del combate Farrell vs Loza, el periódico La Unión comentó que "aumentó el número de fallos injustos con los que la FAB viene perdiendo sus escasos prestigios". ${ }^{68}$ Asimismo el encuentro

67 The Buenos Aires Standard, 8 de octubre de 1922

68 La Unión, 13 de octubre de 1922 
frente a Adán estuvo marcado por otra tensión cuando el segundo del boxeador uruguayo se opuso a que el papel de árbitro lo oficiara el Sr. Eduardo Oromi a quien la FAB había designado en primera instancia. En consecuencia, el Dr. Lisandro Galindez consintió en oficiar. La aparición del Doctor en el ring fue recibida, según The Buenos Aires Standard, "con aplausos, ya que por Don Lisandro es seguramente uno de los deportes más populares de la ciudad". 69

El segundo arribo de Willie Farrell, en mayo de 1924, con su familia, encuentra una Buenos Aires en la que el boxeo se ha legalizado como espectáculo público y rentado. Como condición ambas instituciones rectoras del boxeo se han reunificado en la FAB. Los documentos dejan algunas discontinuidades interesantes. El mismo periódico (Crítica) que a fines de 1922 lo calificaba de tonguero y de haber peleado con oponentes paquetes, ahora rememora aquel paso como una actuación brillante y dice que su abandono frente a Vicente Ostuni no le quita mayores méritos. Otra nota que promociona la próxima pelea contra Joe Walls dice que Farrell es el más completo boxeador que haya actuado en un ring de Buenos Aires. Pero el problema con Farrell es, siempre según Crítica, que "ha perdido todo entusiasmo deportivo [...] el pugilista irlandés solo ve en los match un medio de realizar ganancias materiales". ${ }^{\circ 0}$ Se sugiere entonces que Willie se cuida de poner K.O o derribar a sus oponentes de acuerdo con las apuestas realizadas sobre los resultados de los combates. Tras la pelea con el uruguayo Fernando Villalba en el local de L'Aiglon, Crítica comenta que "luego de su victoria de anoche poco tiene que hacer Farrell entre nosotros. Al público no le interesa su juego. Quiere un box más franco, más noble. Quiere ver cómo se vence en un golpe y no cómo se rompe a un adversario con una tarea lenta y fría, raspando el guante sobre las narices". ${ }^{71}$

Sin embargo, aunque en forma intermitente por el momento, los documentos hallados muestran que Farrell continuó presente en el medio boxístico porteño a través de una serie de viajes entre Londres y Buenos Aires en la que actuó él mismo como agente de enganche para traer pugilistas británicos a la ciudad porteña. El periódico británico Hartlepool Northern Daily Mail, publica en su edición de miércoles 14 de agosto de 1929, que se encuentra de misión por Inglaterra: "Sr. Willie

69 The Buenos Aires Standard, 8 de octubre de 1922

70 Crítica, 22 de mayo 1924

71 Crítica, 23 de mayo de 1924 
Farrell, apodado por los mecenas del music-hall hace unos años como actorboxeador, vino de la Argentina en busca de tres boxeadores ingleses representativos para ir a Buenos Aires la próxima primavera” Luego, un redactor del Leeds Mercury en una nota titulada "Boxeadores para Argentina", comenta, el 11 de septiembre de 1929:

\begin{abstract}
"Cuando visité The Ring anoche, encontré que un viejo favorito había vuelto a ver los eventos en un lugar donde hace años había ganado muchas peleas. Fue Willie Farrell, quien en sus días estuvo en las primeras líneas entre los welter. Farrell ha estado en Argentina y ahora está aquí mezclando vacaciones y negocios. Cuando regrese debe llevar boxeadores británicos para pelear en Argentina, donde me dicen que hay más dinero que buenos boxeadores. Aquí, por supuesto, es al revés. Ahora, supongo que es un hombre de negocios y está bien."
\end{abstract}

Parece que su punto de referencia en Londres seguía siendo la empresa The Ring. Una nota del Birmingham Daily Post de unos meses antes, 28 de marzo, ofrece algunos datos más sobre los enlaces. Allí Farrell declaró que debía regresar a Buenos Aires con un liviano, un peso medio y un welter para mostrar como es el boxeo inglés. Y aclara que "estos pelearán durante la Exhibición de Industrias Británicas que se realizará en Buenos Aires la siguiente primavera.” Aclara además que su búsqueda es un encargo de los hombres del gobierno argentino.

Los británicos lograron realizar una feria propia en Buenos Aires entre el 14 de marzo y el 27 de abril 1931 con la Exposición de Artes e Industrias Británicas. ${ }^{72}$ Un alto valor simbólico tuvo la presencia del Principe de Gales, Eduardo, heredero de la Corona británica, que viajó a Sudamérica para inaugurar la exhibición. El boxeo fue parte de esas exhibiciones y una de las peleas más recordadas fue la de Justo Suárez y Estanislao Loayza en el viejo estadio de River Plate. A esa pelea asistieron el Duque de Kent y el Principe de Gales, duque de Windsor. Aunque no se hallaron por el

\footnotetext{
72 Este era un eslabón más en la rivalidad comercial entre EE UU e Inglaterra. Era una iniciativa para recuperar e incrementar el comercio argentino-británico que estaba perdiendo cada vez más a manos del norteamericano. La iniciativa de la Exposición se barajaba desde 1927. Ese año fue particularmente profundo el descenso del saldo comercial británico con Argentina. Finalmente la exposición fue promovida por Sir Herbert Gibson (Pte. de la Cámara de Comercio británica en Argentina). Se trataba de publicitar mercaderías británicas para aumentar sus ventas. El gobierno británico apoyó esta medida y sumó una exhibición oficial a la del sector privado. Claro que recibió apoyo también del lado argentino. Los vicepresidentes honorarios de esa exhibición fueron: Uriburu (embajador argentino en Londres), el Pte de la Suprema Corte, José Figueroa Alcorta, el ministro de agricultura Horacio Beccar Varela. Al respecto ver, Di Lisia, Maria Silvia y Lluch, Andrea (editoras) Argentina en exposición. Ferias y exhibiciones durante los siglos XIX y XX. Colección Universos Americanos. Sevilla, Consejo Superior de Investigaciones Científicas, Buenos Aires, 2009.
} 
momento documentos que confirmen finalmente la participación de Farell en este asunto, sí poseemos indicios sobre la participación de otros miembros de su grupo. Una toma fotográfica de aquella velada vuelve a mostrarnos a McCarthy de rodillas atendiendo al duque de Kent en el estadio de la calle Tagle.73 Parece entonces que la red continuaba funcionando a comienzos de la década de 1930 y Farrell prolongó sus viajes y la red de contactos en Argentina. Pero su lugar se había movido. Al menos ahora parecía más patente que él mismo actuaba como un agente comercial y oficial de enlace, o como dice el periódico británico, como un hombre de negocios. Las siguientes noticias de que disponemos lo vuelven a ubicar en este rol. El The Day mail de 27 de junio de 1931 informa que:

“el ex actor-boxeador y promotor de la empresa argentina de boxeo, llegó a Inglaterra con una comisión para firmar con boxeadores y llevarlos a las repúblicas de Sudamérica. El primero en aceptar la oferta ha sido el ex campeón de peso ligero de Gran Bretaña, Harry Mason”

Para la década de 1930, Willie se había domiciliado en la Argentina. Pero su labor lo llevaba constantemente a su primera patria. Otro periódico británico, el Birmingham Daily Post de 28 de marzo de 1939 comentó que:

"Willie Farrell, conocido hasta antes de la guerra como el actor boxeador y ahora domiciliado en Buenos Aires, quiere contratar los servicios de un británico para cumplir con Breschia, campeón argentino, en un estadio local a principios de mayo. Menciona como candidatos elegibles Georges James y Jack London, quienes se reunirán el próximo lunes".

Por aquellos tiempos Farrell también actuó como profesor y director de Julio Mocoroa, quien fue uno de los más grandes boxeadores locales, que rivalizó con el máximo ídolo Justo Suarez, apodado el Torito de Mataderos.

Hasta aquí la trayectoria reconstruida con los datos disponibles. Willie Farrell falleció en Buenos Aires, en el Hospital Británico, el 10 de julio de 1962. Su certificado de defunción acusa que la causa del deceso fue una trombosis cerebral generalizada. Sus restos fueron llevados al cementerio de la Chacarita. Algunos

73 La imagen fue publicada posteriormente en El Gráfico N 2179 de 06 de Junio de 1952, en el marco de notas memorísticas escritas por Marcelo Peacan del Sar, quien fuera presidente del Boxing Club. 
medios como Clarín, El Gráfico y Buenos Aires Herald registraron el suceso en una breve columna.

\section{Consideraciones finales.}

Las últimas décadas del siglo XIX y la primera del siglo XX fueron cruciales en la estructuración del boxeo inglés que es, a grandes rasgos, la modalidad predominante en la actualidad. En aquel momento comenzaron los impulsos de algunos hombres para difundirlo desde Buenos Aires y lograr su profesionalización. Mientras tanto la ciudad se iba convirtiendo en un puerto de paso para muchos boxeadores trashumantes. Los primeros campeones "nacionales" fueron boxeadores migrantes que arribaron desde el otro lado del Atlántico y que actuaron aquí desarrollando un rol de docencia y de propaganda. El período de entreguerras fue un momento de apogeo y popularización a nivel mundial y, con Firpo, vio surgir en el Río de la Plata uno de los máximos ídolos del pugilismo. La llegada de Willie Farrell a Buenos Aires no fue azarosa. Los documentos trabajados hasta el momento permiten postular algunas conexiones y subrayar algunos lazos. En ese sentido hemos intentado ver a Willie y a los otros hombres y grupos que se mencionaron en este trabajo, no solo a partir de las relaciones que mantuvieron, sino que también hemos tratado de ver a unos a través de los otros. Si Farrell era conocido en Londres por el apodo que sus mecenas del Music hall le asignaron, como actor-boxeador, en Buenos Aires sus mecenas locales y los medios destacaron siempre su condición de irlandés, aun cuando Willie hubiera nacido en Londres. ¿Por qué? ¿Acaso tenía que ver con el origen del agente de enlace más importante, Mccarthy?

En todo caso sí debemos mencionar la siguiente paradoja: aunque parece ser que el pugilismo estuvo desde muy temprano arraigado en una cultura de movilidad, también es cierto que el boxeo estaba estrechamente asociado con las concepciones de lugar e identidad. Era un deporte que, en muchos aspectos, estaba ligado a localidades y ciudades particulares. La identidad del pugilista se incluía en los programas y anuncios de las peleas y, por lo tanto, era parte de la identidad pública del “artista”. En este sentido, a nivel global los boxeadores irlandeses tenían fama de ser los más agresivos. En Estados Unidos los dirigentes políticos usaban boxeadores irlandeses en las elecciones como "bateadores" para "convencer" a los votantes que sufragaran a su favor. En New York, entre 1840 y 1860, los irlandeses componían el 
$53 \%$ de los boxeadores. Presentar a Willie Farrell como irlandés, ¿̇era entonces parte de la estrategia de engrosar su fama y su condición bravía para atraer mayor público? Aunque por aquellos tiempos, el mercado norteamericano estaba superando al británico y esto también se verificaba para el campo del boxeo, Gran Bretaña seguía siendo un centro de autoridad para la actividad pugilística. Esto se expresa por ejemplo en las sospechas que Farrell despierta en la prensa rioplatense: "nos parece dice La Unión- que se encuentra en el final de su carrera; de otro modo no hubiera salido de Inglaterra donde, moral y materialmente, le hubiera convenido más que en estas hospitalarias playas" 74

Sin embargo, la biografía de Farrell muestra otros costados de la relación entre centros y márgenes. Evidentemente, si Farrell dejó aquel centro para migrar a lo que era un margen por aquel entonces (1922), pues en Buenos Aires el pugilismo profesional aun no era una actividad lícita, debemos al menos aceptar las potencialidades que dicho margen representaba, durante el período de entre guerras, para un boxeador en el ocaso de su carrera profesional y en el paso al desempeño de otros roles dentro del mismo campo, como entrenador, manager o promotor. De alguna manera, era también lo que de un modo un tanto etnocéntrico, proponía aquel periódico británico según el cual Inglaterra tenía buenos boxeadores y Buenos Aires el dinero para pagar por ellos. Por otra parte, este caso singular tiene la virtud de complejizar una visión que buscara hacer del boxeo argentino una historia enmarcada solamente en los límites de lo nacional. Encontramos nuevos significados sobre la práctica del pugilismo en la región rioplatense al conectarla con un contexto más amplio que incluya vínculos entre hombres, grupos e instituciones a ambos lados de la cordillera de los Andes, del Río de la Plata y del Atlántico. A través de un recorrido biográfico significativo, la difusión de la práctica pugilística se nos descubrió ramificada más allá de las fronteras nacionales y en distintos contextos.»

\section{Bibliografía.}

ALABARCES, P. "Deporte y sociedad en América Latina: un campo reciente, una agenda en construcción"; en Anales de Antropología, ED. UNAM. Vol. 49 N.1, 2015 .

74 La Unión, 17 de octubre de 1922 
Anuario del Club de Gimnasia y Esgrima. 110 años en la historia del deporte argentino. Buenos Aires, 1990

AUZZANI, Ángel, El boxeo. Córdoba, ED Ediciones Deportivas Ex.Conde. 1953

BELL, Leslie. Bella of Blackfriars. Londres, Odham Press Limited. 1961.

DI LISIA, Maria Silvia y LLUCH, Andrea (editoras) Argentina en exposición. Ferias y exhibiciones durante los siglos XIX y XX. Colección Universos Americanos. Sevilla, Consejo Superior de Investigaciones Científicas, Buenos Aires, 2009.

ESTOL, H. Vida y combates de Luís Ángel Firpo. Buenos Aires, Ediciones Bell, 1946

GINZBURG, C. La latitud, los esclavos, la Biblia: Un experimento de microhistoria. Disponible en http://www.jcortazar.udg.mx/sites/default/files/GINZBURG.pdf

OATES, C., Del boxeo. Buenos Aires, Ediciones Punto de Lectura, 2012.

ORIANI, J. Generalidades del box. Buenos Aires, FAB, 1968

PUTNAM, Lara. "The Transnational and the Text-Searchable: Digitized Sources and the Shadows They Cast”. American Historical Review. Vol. 121, n. 2, 2016, p. $377-402$

REVEL, J. Micro versus Macro: escalas de observación y discontinuidad en la historia. En Tiempo Histórico $\mathrm{N}_{2}{ }_{2}$ /15-16/ Santiago de Chile 2011.

SAÍTTA, Sylvia. Regueros de tinta. El diario Crítica en la década de 1920. Buenos Aires, Ediciones Siglo XXI, 2013.

SEIGUER, Paula. Jamás he estado en casa. La Iglesia anglicana y los ingleses en la Argentina. Buenos Aires, Editorial Biblos, 2017.

SCOTT, Rebecca J. "Small-Scale Dynamics of Large-Scale Processes", en The American Historical Review, Vol. 105, No. 2 (Apr., 2000), pp. 472-479

TAYLOR, Matthew, "The global ring? Boxing, mobility and tansnational networks in the anglophone world, 1890-1914"; en Journal of Global History, Volume 8 02/07/2013, pp231-255

VIALE, Cesar, El deporte argentino, Buenos Aires, A. García Santos, 1922.

\section{Fuentes.}

\section{Publicaciones de Buenos Aires:}

Crítica

El Gráfico

Caras y Caretas

Buenos Aires Herald

The Buenos Aires Standard

La Nación, La República

La Unión

La Razón

Última Hora 


\section{Publicaciones británicas:}

Birmingham Daily Post

The Day mail

Leeds Mercury

Hartlepool Northern Daily Mail

\section{Otros documentos:}

Certificados de arribos del Museo de la Inmigración, Buenos Aires.

Certificados del registro Civil de las Personas, Buenos Aires. 